\title{
The Lack of the Frame and Transformations of the Concept of Art*
}

\author{
TANG Ke-bing \\ Southwest University, Chongqing, China
}

\begin{abstract}
The frame should not only be regarded as an external physical framework of artworks, but also the boundary mark of identifying the art and reality. Within classical space contained by the frame, the values of reason, order, and clarity work to achieve a coherent picture space uniting, through the agency of the frame and the space represented with the space occupied by the beholder. The resistance on "frame despotism" and "dismemberment" of picture by avant-garde artist exposes the illusory reality created by perspective and verisimilitude, which deconstructs the false aesthetic relationship of frame and picture. Analysis on frame by modernist art builds its art value.
\end{abstract}

Keywords: frame, boundary, linear perspective, optical realism, modern art, artistic autonomy

\section{Introduction}

It is easy to ignore such a "ridiculous" question: Why is the frame always attached to paintings, a pedestal to a statue, an embellishment or ornament to what is already present (the artwork itself)? In other words, what has produced and manipulated the frame puts everything to work in order to efface the frame effect, most often by naturalizing it to infinity (Derrida, 1987, p. 73). We have grown so accustomed to viewing artworks in a seemingly infinite variety of contexts and situations that we do not see the frame itself. This is true not only of artworks whose frames tend to understate, as in modernism, but also those that employ the most assertive physical frames, as in the art of the baroque. How has this situation come about? One conceivable answer is that the striking imbalance of inquiry that the artwork has received in comparison to its frame has not helped us to see the role, function, or purpose of the frame in the construction of the artwork, or how it contrives a meaning for itself and for that which it encloses (Duro, 1996, p. 1).

It is against this tendency to ignore the frame that this present paper is directed. The frame should not only be regarded as an external physical framework of artworks, but also the boundary mark of identifying the art and reality. Within classical space contained by the frame the values of reason, order, and clarity work to achieve a coherent picture space uniting, through the agency of the frame and the space represented with the space occupied by the beholder. The resistance on "frame despotism" and "dismemberment" of picture by avant-garde artist exposes the illusory reality created by perspective and verisimilitude, which deconstructs the false aesthetic relationship of frame and picture. Analysis on frame by modernist art builds its art value.

\footnotetext{
* Acknowledgements: This paper is supported by the Fundamental Research Funds for the Central Universities of Ministry of Education of China (Grant No. SWU1509387).

TANG Ke-bing, lecturer, Ph.D. candidate, Department of Literature, Southwest University.
} 


\section{The Frame as a Marker of Boundary or Border}

The role of the frame in the presentation of a picture fulfils some or all of the following functions: the protection of the painting; its display and physical attachment to the wall; the enhancement of subject and color scheme while remaining subordinate to the picture; the definition of the picture's perimeter and focusing of the spectator's attention on the subject; the provision of an area of transition between the real world and that of the picture; the creation of harmony with the surrounding interior decoration; and the isolation of the picture from a distracting background (Mitchell \& Roberts, 1996, p. 8).

The most obvious functions that frames serve are practical and decorative. Frames are indeed decorative; they can be used to coordinate a painting with the architecture and furnishings of a room, or they can be used to provide an elaborate casing to show off an expensive work of art, or an impressive setting to glorify a sacred image. And frames are indeed practical; by protecting the vulnerable edges and corners and the delicate surfaces of paintings, they provide a practical means for holding and hanging the canvas, and they thereby enhance its portability. But frames are not merely protective and decorative packaging: They serve important artistic functions as well.

Consider again the frame's role in enabling portability. Portability not only raises the practical issue of protecting the panel or canvas, it also raises the aesthetic problem of the painting's relations to its immediate surroundings. With a wall painting, the surroundings are more or less given and may even be delineated by an architectural border; the painting can be designed with those surroundings in mind. With an easel painting, the ultimate destination of the work is often unknown. The frame provides its border, insulating the easel painting from the colors and patterns of the walls it encounters, and limiting the interaction with neighboring works. It helps to focus our attention by delineating the boundaries of the work (Savedoff, 1999, p. 350).

Alberti, as we know, regards the "boundaries" of the work as the most important "viewing frame" of composition and the support of focus perspective playing a role in Della Pittura. Alberti points out clearly:

Then I establish a point in the rectangle wherever I wish; and as it occupies the place where the centric rays strikes, I shall call this the centric point. The suitable position of this centric point is no higher from the base line than the height of the man to be represented in the painting, for in this way both the viewers and the objects in the painting will seem to be on the same plane. (Alberti, 1956, p. 55)

That is to say, the viewing frame based on the consciousness habit, makes a visual window for viewers in advance and through this window, we can see the objects created by painter. On the contrary, if the perspective focus or central point can not be found in the reproduced picture, the images framed present a plane of mess and disorder and are easily mixed with external physical space. It is just like the defocus in shoot. For the viewers, vague images are difficult to appear the "real" beauty. In a word, consciousness of frame affects not only on composition of artist directly, but also the expression of artistic values.

Nicolas Poussin comments on in a letter, sent from Rome in 1639, to his patron, Paul Fréart de Chantelou, advising him of the dispatch of The Israelites Gathering the Manna to Paris. The painting depicts an episode from the Biblical book of Exodus in which the Jewish people are saved from starvation by the miraculous appearance of a food - the manna - that falls from the sky. Here we want to focus on one brief passage in the letter, where Poussin comments on the need for a frame: 
Once you have received your painting, if you like the idea, I ask you to adorn it with a frame; this is necessary in order that when viewing it in all its parts the rays of the eye are focused and do not become distracted by the impression of other neighboring objects which risk becoming confused with those of the painting. (Poussin, 1911, pp. 20-21; Lebensztejn, 1988, p. 37)

Here, the frame can not only reflect the classicism painting theory, but also imply the importance of frame in the process of creating of art. He asked the sponsor to make a frame, which reflects that he worried the complicated and exaggerated decorations of Baroque Style would destroy image's classic style. So the frame can separate image to be presented from irrelevant objects. In terms of separation, frame not only represents a clear boundary, but also plays other roles. Within the space contained by the frame the values of reason, order, and clarity work to achieve a coherent picture space uniting, through the agency of the frame and the space represented with the space occupied by the beholder.

The philosopher Immanuel Kant comments on this question in the Critique of Judgment of 1790 in a section of his thesis titled "Elucidation by Examples". Those of you who know this text will agree that Kant's idea of what inheres and what is external to a judgment of taste is, at best, counter-intuitive. Among them he cites a colonnade around a building, clothing on a statue, and picture frames. With respect to the frame, he calls it a supplement and remarks, "for all they do is to make the form intuitable more precisely, determinately, and completely, while they also enliven the presentation by means of their charm, by arousing, and sustaining the attention we direct toward the object itself' (Kant, 1987, p. 72). Kant's remark seems almost identical to that of Poussin, especially with reference to sustaining the attention we direct toward the object itself. But Kant's point is not quite the same as Poussin's. In the same passage, he distinguishes between ornament, what he calls "parerga", and the artwork in itself in noting,

if the ornament itself does not consist in beautiful form but is merely attached, as a gold frame is to a painting so that its charm may commend the painting for our approval, then it impairs genuine beauty and is called finery. (Kant, 1987, p. 72)

\section{Optical Realism: Innovation in Impressionist Frames}

In Kant's opinion, color and tone are just the complement of form reproduction and they do not have the form of beauty themselves, so they are not the constituent of the internal order of beauty. Kant making such separation is obvious to clarify the essential difference between internal beauty and relevant objects, while such difference has its realistic basis. The frame of Baroque Style artworks is always a gold one and its gorgeous appearance can match the picture with grand and complex style. However, if the golden frame is used on the early impressionist pictures, that will be a problem.

The Impressionists' evolutionary exploration on light and color affects directly on their choices about frame. For example, Seurat and Van Gogh decide the shape and color of the frame before painting. Degas designs and makes the frame model in person. In order to show the same color atlas with right ray, they make the base on canvas by white pigment and paste, and then make different color on the canvas evenly. Thus, when the natural light shines on the picture, raster will be distributed evenly on the picture. Gilded frames, "whose gold surfaces flicker and glow with reflected light, would diminish the effects the Impressionists were attempting to achieve with pigment" (Easton \& Bark, 2008, p. 611). So, the Impressionists choose white variegated frame to take place of gold one. This tiny change attached great importance to art critics of vision. Laforgue analyzed profoundly that 
in all kinds of exhibitions, dependent painters used reasonable and imagined frame to replace the old golden frame, while the latter one was the conventional one used by professional academism. Paintings showing different images such as green grass shining under the sun, the beautiful scenery in winter, and the colorful indoor setting require different styles of frames which only can be supplied by painters themselves. It is just like that women know what to wear, how to make up, and choose which decoration on their wall (Ding, 1997, p. 173). Thus it can be seen that the great importance on frame from impressionist painters is based on artistic pursuit which means realizing the Arnason's "optical realism". "Optical realism" is a kind of visual reality, which is different from false reality created by geometric perspective. Impressionist painters claimed that painting was not only to maintain the appearance of objects, but the form of sunshine and shadow, reflection light on water and flowing clouds. The endless change is the world we are watching for. The world is not the fixed and absolute illusion limited in the frame by gazing, but the ever-changing sceneries beheld by moving eyes (Arnason, 1986, p. 21).

Although the Impressionists' revolutionary explore on light and color have challenged the tradition of pictorial representation since renaissance, the Impressionists still make the nature as objects and the images presented on picture are complete and pure. Even if Cézanne, the post-impressionist painter, reconciled the contradiction between color and shape by reforming monocular perspective; painting is to pursue for "second nature" and art is the external embodiment of beauty concept. While in the 20th century, "modernism" in art including Fauvism, Cubism, and Abstract Expressionism raised a new movement on image dismemberment between figurative art and abstract art, as a result, art developed to independent beauty, getting rid of traditional aesthetics limitation. When avant-garde artists launched a fierce attack on traditional aesthetics values by practical action, the frame became the object of "dismemberment".

\section{Resistance on the Frame: Modern Art and Its Artistic Autonomy}

In the history of sculpture art, Rodin is the first one to remove the statue base. His The Burghers of Calais does not have base at first. While the first painting without a physical frame is Portrait de Gertrude Stein created by Picasso in 1906. In the opinion of these innovators, removing or abandoning the frame means resisting against authority and destroying the old order. Fontana is more aggressive and he is the first one to break the linen canvas to show that the basis of painting is just a plane. This anti-tradition artistic action making the frame have the possibility to be analyzed from the perspective of semiotics and art sociology. Schlosser thinks that just like the relationship between introduction of eye level and despotism high civilization, the frame imagination and Greek art have the similar relationship. Frame is related to perspective, that is to say, person is framed and the scope is limited. This frame rule plays the dominant role in Renaissance, which is called as "frame despotism" by Schlosser (Hillebrecht, 1989, pp. 141-142). This means that the question of frame is not only a aesthetic question, but also refers to culture and the discipline of political order and the "frame despotism" centered by rationality and order is precisely what modern artists resist.

We should pay attention to that the resistance on traditional frame by modern artists reflects that "resistance on frame" is a kind of notice and care about frame. That is to say, frame has become the important issue about how to understand artwork and express artistic concept. Mondrian wrote in a letter: 
So far as I know, I was the first to bring the painting forward from the frame, rather than set it within the frame. I had noted that a picture without a frame works better than a framed one and that the framing causes sensations of three dimensions. It gives an illusion of depth, so I took a frame of plain wood and mounted my picture on it. In this way I brought it to a more real existence. (Mondrian, 1946, pp. 35-36)

It can be seen that these artists regard the frame of artwork as an artistic question with core value, but removing frame does not mean that artwork is so dependent that does not need framing. In fact, the physical frame can be abandoned, but the perceptual frame of composition can not be removed because frame is not just a question of boundary. Mondrian knows clearly that frame refers to the reproduction of three-dimensional space of picture, so modern artists come back to the "planarity" of picture though various ways.

Like the post-impressionist, Fauvism abandoned the sharp contrasts of light and shade and reached the color space to the full. In the artwork Joy of Life by Mattis, the figure outline is skew and thin and the space surrounded by blinking plants is likely to break the limitation made by boundary of picture. If the Fauvism maintains the basic outline of some certain objects, Cubism artists make the dismemberment and destroy to the maximum on the form of objects, which has become the strong driving force for developing to Abstractism art (NIU, 2002, p. 263). Cubist's abstract collage compares the "trace" on the canvas to symbol and ornamental, not a complete plane. It is never like a mirror to simulate nature and reflect reality. Putting all these fragments on the picture is just like an unfinished draft to reveal that it is drawing. The meaning of picture is not focusing on the surface, but to reproduce the meaning from viewer's various perspectives. That is to say, what we see is not the image of a picture, but some semi-abstract symbols from the perspective of viewer. Especially in the period of "comprehensive painting", the concrete objects such as violin, tree, tanks, and house in the picture are replaced by pure color lump and geometric figure. Cubist develops into complete abstract after getting rid of concrete restrain. Non-figurative abstract art such as abstract expressionism represented by Kandinsky, hard-edge geometry abstract marked by Malevivch's suprematism, and "new constructivism" represented by Mondrian inherits and surpasses pioneer route of Cubist and continues the abstract. The modern art develops into the "brutal art" called by Nietzsche.

No matter Cezanne's way of making landscape theme to geometry with semantic function, Matisse's "emotional expression" in his painting or the Cubist's "sense disintegration and idea forming" (claimed by Braque), the trend of modernism art development is clear; tree-dimensional space in traditional painting is disassembled or flattened to irrational abstract plane, in order to restore the nature and freedom of line and color of the picture. Thus "art noumenon" is endowed with absolute "art will". To reach this restoration of authenticity, the false focus perspective should be disassembled. Jean Clair said

the generally accepted idea is the modern history from Cezanne to minimalists is a struggle history in which artists liberate themselves from shackle of unnatural perspective. The artists regard painting as "carrier" rather than "window". If the painting is regarded as window, eyes will be fallen into illusory space which is totally different from natural space. If we consider the painting as carrier, what we notice is its object-hood. The visualized space of this kind of painting shows in front us with non-focus and isotropous image. (Clair, 2002, p. 264)

In other words, if the frame is regarded as window, it has cut the continuity of visual world and boundary will produce the centre in the sense of space. The center is constructed through fixed point perspective, so that the frame can produce the effect of in-position viewing by making the "empathy" to the maximum. Therefore, in 
traditional artworks, painting always follows the rule of boundary and center. If the painting is hung on askew, the center will be changed, which will affect the understanding of painting and expression of beauty. Many modern artworks do not have the difference of up and down. So to distinguish the up and down of an abstract painting is always a problem. Sometimes people hang the painting on the wall bottom up. Artists sometimes say that there is no fixed hanging method of his painting and people can turn his painting 90 degree every few weeks, so that people can observe from different directions (Harries, 1979). For the abstract art, the image in the painting does not follow the habit of "boundary" and "center". Artists remove the mysterious relationship between frame and in-position viewing with the attitude of "denying empathy" and then deconstruct the false coupled relationship of the artwork to its frame.

\section{Conclusion}

Transformation of art's concept and style always implies the discourse related to "frame". The frame firstly as a mark of boundary or border, separates the painting space and physical space and is embedded in the artwork at the same time. For the viewers, illusion and limitation of aesthetic distance created by frame obey with rules of the monocular linear perspective based on optics and geometry. For this reason, viewers can enter the state of "attentive observation". However, modernism artists reveal the false reality brought by perspective and reality by cutting, flattening, and dismantling of the picture and remove the false coupled discourse relationship between frame and image. In fact, the "anti-frame" action that deconstructs function of frame by abstract art builds its art concept.

\section{References}

Arnason, H. H. (1986). A history of modern art: Painting, sculpture and architechure. New York :Abrams, Inc..

Alberti, L. B. (1956). On painting. (J. R. Spencer, Tans.). New Haven: Yale University Press.

Clair, J. (2002). Sam Szafran. In J. XU \& X. J. JIAO (Eds.), Figurative expressionism collection. Hangzhou: China Academy of Fine Arts Publishing House.

Derrida, J. (1987). The truth in painting. (G. Bennington \& I. McLeod, Trans.). Chicago and London: University of Chicago Press. Ding, N. (1997). Dimensions of duration toward a philosophy of art history. Beijing: SDX Joint Publishing House.

Duro, P. (1996). The rhetoric of the frame: Essays on the boundaries of the artwork. Cambridge: Cambridge University Press.

Easton, E., \& Bark, J. (2008). Pictures properly framed: Degas and innovation in impressionist frames. The Burlington Magazine, 150, 603-611.

Harries, K. (1979). The meaning of modern art. Evanston: Northwestern University Press.

Hillebrecht, M. K. (1989). The psychology of modern art. (Y. P. CHEN, Trans.). Shanghai: Shanghai Literature and Art Publishing House.

Kant, I. (1987). Critique of judgment. Indianapolis/Cambridge: Hackett Publishing Company ,Inc..

Lebensztejn, J. C. (1988). Framing classical space. Art Journal, 47, 1.

Mitchell, P., \& Roberts, L. (1996). A history of European picture frames. London: Merrell Publishers.

Mondrian, P. (1946). Eleven Europeans in America. The Museum of Modern Art Bulletin, XIII, 4-5.

NIU, H. B. (2002). Modern western aesthetics. Shanghai: Shanghai People's Publishing House.

Poussin, N. (1911). Correspondence de Nicolas Poussin (Correspondence of Nicolas Poussin.). C. Jouanny (Ed.). Paris: Archives de l'art français.

Savedoff, B. (1999). Frames. The Journal of Aesthetics and Art Criticism, 57, 3. 